\title{
Quantifying Evaluation and Grading of Cultivated Land Fertility: A Case Study of Huaping, China
}

\author{
Yuan Lei ${ }^{1,2}$, Yang Kun ${ }^{1,2 *}$, Chen Guoping ${ }^{3}$ \\ ${ }^{1}$ School of Information Science and Technology, Yunnan Normal University, Kunming, China \\ ${ }^{2}$ Engineering Research Center of the Ministry of Education on Geography Information Technology \\ of Western Resource Environment, Kunming, China \\ ${ }^{3}$ Faculty of Land Resource Engineering, Kunming University of Science and Technology, Kunming, China
}

Received: 15 May 2018

Accepted: 2 August 2018

\begin{abstract}
The level of cultivated land fertility (CLF) determines food production and quality directly. Therefore, research on evaluating CLF has always been a focus of attention in Chinese academia. Aiming at shortcomings of methods for evaluating CLF presently, this paper proposes an integrated method to evaluate and grade the CLF-adopted GIS, Delphi, analytic hierarchy process (AHP), fuzzy mathematics and comprehensive index model. Furthermore, based on data of the survey project of CLF in Huaping, this paper carried out an empirical study using this method. The result demonstrates that the methods are more scientific and reliable. This is reflected in the following aspects: First, the process of evaluation and grading of CLF is combined with qualitative analysis and quantitative analysis, which make the results more close to the objective reality. Second, the results of the evaluation and grading not only achieved a match between quantitative expression and spatial visualization, but also demonstrated the differences of CLF in quantity and space. Through this study, we hope that this method can further enrich the theory and technology of CLF evaluation to some extent, and also provide a good reference for similar study in other regions.
\end{abstract}

Keywords: cultivated land fertility, GIS analysis, AHP method, fuzzy comprehensive evaluation

\section{Introduction}

Cultivated land is an important means of production for humans to obtain food. The level of CLF is the result of long-term comprehensive effects of various natural and human factors. Because the CLF level determines grain yield and quality directly, the study on the evaluation and grading of CLF has always been

*e-mail: kmdcynu@163.com a hot spot for academics and government departments [1]. For example, Russia carried out land evaluation in order to find the relationship between land tax and land quality in 1877 . The United States proposed the Storie Index Grades and Cornell Evaluation System to replace the previously used methods for yield evaluation in 1933 [2], and promulgated the Land Potential Classification System in 1961. The German Ministry of Finance proposed the Regulations for the Evaluation of Farm Lands in 1934. The Food and Agriculture Organization of the United Nation (FAO) released the Land Evaluation Framework in 1976 [3]. China also formally started the 
Investigation and Quality Evaluation of Cultivated Land Fertility in 2002.

Moreover, as far as evaluation methods are concerned, many different methods have also been used in urban landscape planning, land use, land use change prediction, evaluation and grading of CLF, such as Delphi [4-6], AHP [7-8], fuzzy mathematics [9-11], GIS [12-16], neural network [17] or decision tree [18-21]. Urban landscape planning means determining the future situation of urban land. In this case, it is necessary to use the above methods to predict how the land has changed over time and the effects of natural factors and human activities on the land. In this way, successful and sustainable landscape planning studies can be achieved. In the study of determining land cover and green area changes related to urban areas and their surrounding environments, the above methods can better reveal that land use change is caused by human activities and natural factors. Land cover is one of the most important data points used to demonstrate land-use change, especially human activity. Production of land use maps can be done by using different methods on satellite images. Some studies have produced land cover maps of the controlled classification technique over Landsat satellite imagery. By using land cover maps, the changes in urban development and green areas over time have been evaluated. At the same time, the relationship between changes in land cover over time and changes in the urban population have been carried out [22-27]. However, up to now there has not been a well-established theoretical and technical system for evaluating and grading CLF [28].

In recent years, with the rapid development of GPS, GIS and remote sensing (RS), combining 3S technologies with existing methods for evaluating and grading CLF has become a new idea. Based on this research perspective, this paper focuses on the technical methods and implementation of the evaluation and grading of CLF. The idea of this thesis is as follows: first, based on the data of the survey project of CLF in Huaping, a county in Jinsha River of China, the paper uses GIS spatial analysis technologies, Delphi, AHP and fuzzy mathematics to determine the evaluation index system of CLF and the membership and weight of these indices. Secondly, a comprehensive index model of cultivated land fertility (CIMCLF) was constructed to study the quantitative evaluation and grading of CLF in the study area. Therefore, this study is also a useful exploration of spatial information technologies and innovative statistical analysis techniques in the evaluation and grading of CLF. We expect to establish a set of technical systems and work ideas of data visualization, evaluation automation and result quantification through this research. This is of great significance for enriching theory and the methodological system of evaluating and grading of CLF, and expect to provide a good reference of method for similar research. At the same time, the research results can also provide a basis for the precise management and sustainable use of cultivated land in the study area, which is extremely important for sustaining social stability and sustainable development in China.

\section{Material and Methods}

\section{Study Area and Data Sources}

The study area is located in the middle reaches of the Jinsha River, China. This is the juncture area of the northwestern part of Yunnan Province and the western part of Sichuan Province. It is a typical subtropical valley climate zone, with an average annual temperature of $19.8^{\circ} \mathrm{C}$ and an average annual precipitation of $1039.0 \mathrm{~mm}$. The terrain is also quite different. The relative elevation is $2183.3 \mathrm{~m}$. The soil

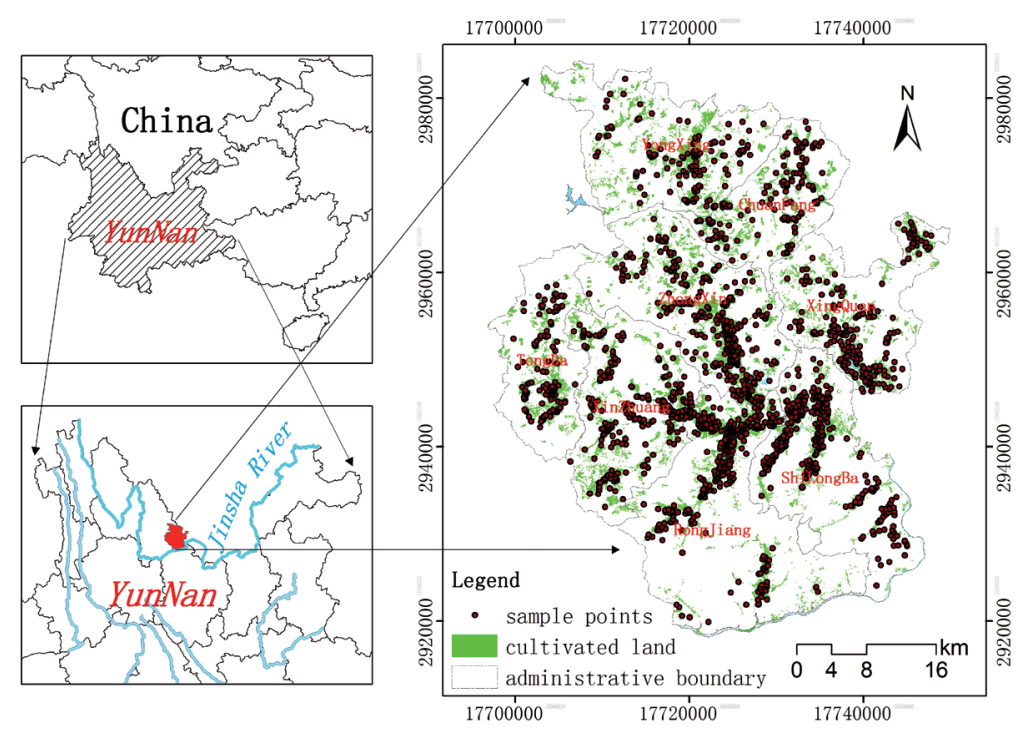

Fig. 1. Spatial distribution of sampling points in the study area. 

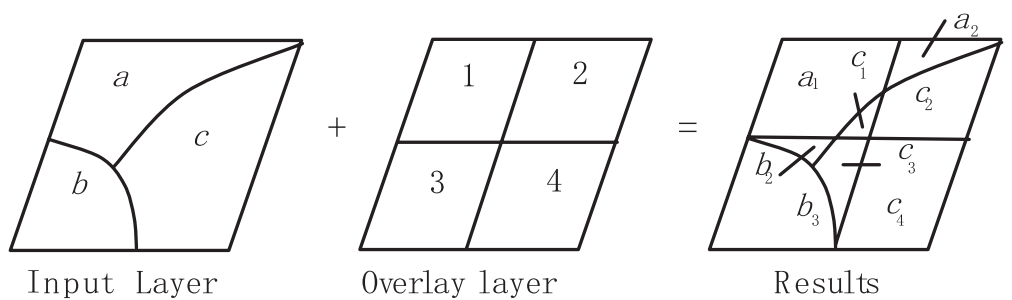

Fig. 2. Schematic of spatial overlay analysis principle.

parent material is mainly composed of alluvial, slope wash and quartzite residue. Furthermore, soil types are very abundant in the study area, which consists of 8 soil classes, 15 subclasses, 28 soil genus, and 41 soil species. The distribution of soil types has obviously vertical differentiation characteristics:

- Above $2600 \mathrm{~m}$ is a distribution zone for brown soil.

- From $2250 \mathrm{~m}$ to $2600 \mathrm{~m}$ is a distribution zone for yellow-brown soil.

- From $1600 \mathrm{~m}$ to $2300 \mathrm{~m}$ is a distribution zone for yellow-red soil.

- From $1200 \mathrm{~m}$ to $1600 \mathrm{~m}$ is a distribution zone for red soil.

- Below $1200 \mathrm{~m}$ is a distribution zone for brown-red soil.

A total of three types of data take part in this study. The first is land use status data. The second is weather data and the third is soil status data. The land use status data include basic geographic information such as the distribution of land resources, the slope and the elevation of the study area. The weather data include annual mean temperature, annual precipitation and so on. The soil status data include soil management, soil nutrients and soil properties. In order to obtain the soil status data, we collected the data from 2515 sampling points in the study area. These sampling points contain a total of 591 key sampling points and 1924 auxiliary sampling points. These sampling points were distributed in 8 townships in the study area (Fig. 1). The layout of these sample points is according to the standard of each $7-13 \mathrm{hm}^{2}$ areas as a unit with " $\mathrm{S}$ " shape arranged evenly. These sampling points cover 8 soil classes, such as red soil, yellow-brown soil, paddy soil, alluvial soil, purple soil, calcareous soil and meadow soil. Besides, we also investigated the perceptions of farmers from aspects of fertilization management, conditions of cultivated land, physicochemical characteristics of the soil and so on. At the same time, we utilized GPS technology to obtain the spatial coordinates of each sampling point.

\section{GIS Spatial Overlay Analysis Technology}

GIS spatial overlay analysis technology refers to the superposition for two or more sets of thematic features of graphics in the same region, the same scale and the same mathematical basis but different information; then according to the intersection of various elements and polygon boundary, or polygon properties to create a new feature layer with multiple attribute combinations [29] (Fig. 2).

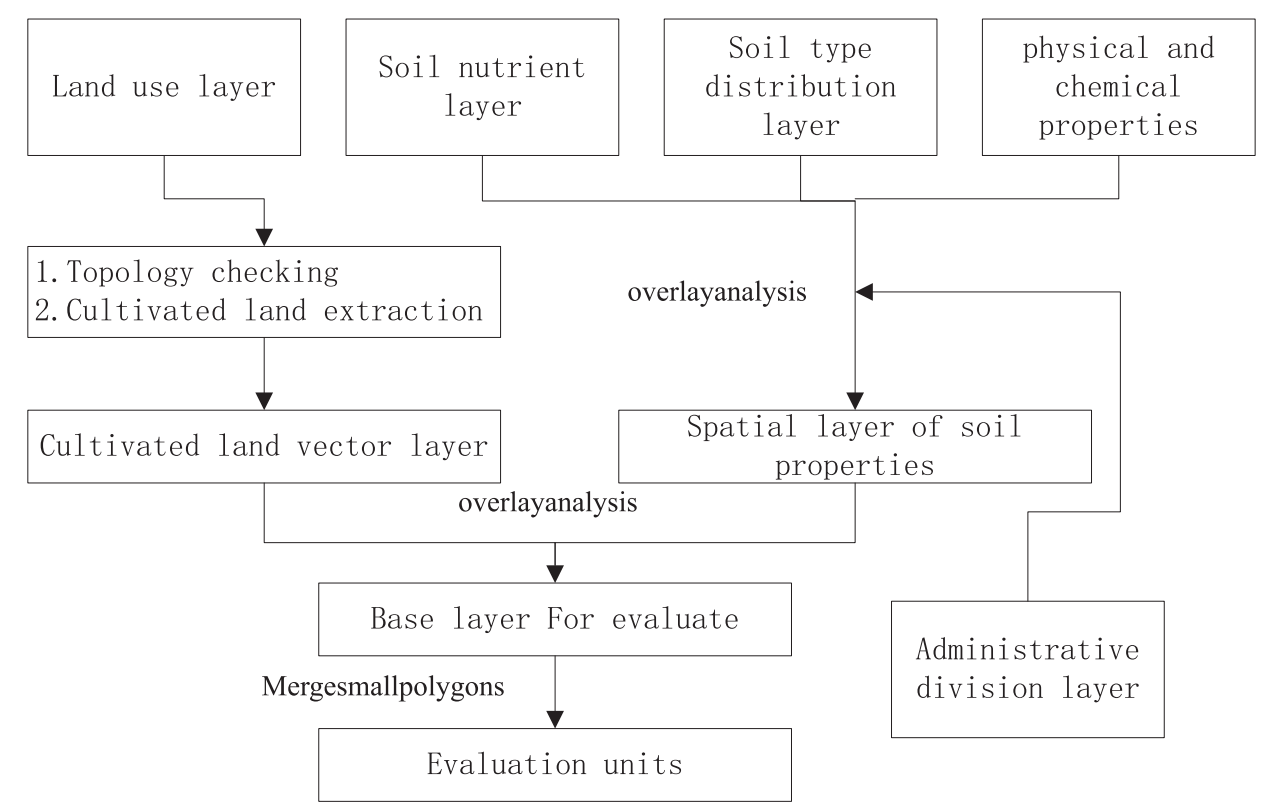

Fig. 3. Process of overlay analysis. 
In this paper, the spatial overlay technologies of GIS are used to determine evaluation units of CLF. The approach is that the administrative division layer, land use layer, soil nutrient layer and soil type distribution layer are overlaid to segment these evaluation units by these technologies, which makes the evaluation units possess clear spatial boundaries and administrative affiliation. After the above processing, we got 8400 evaluation units (Fig. 3). An evaluation unit is a basis for the evaluation and grading of CLF. It is convenient for carrying out multi-angle spatial statistics and analysis for CLF in subsequent periods.

\section{Kriging Spatial Interpolation Method}

Kriging spatial interpolation method is one of the optimal unbiased estimation methods for regionalization variables without sample points [30]. As a kind of weighted moving average interpolation method, its advantage is to get estimated values of independent
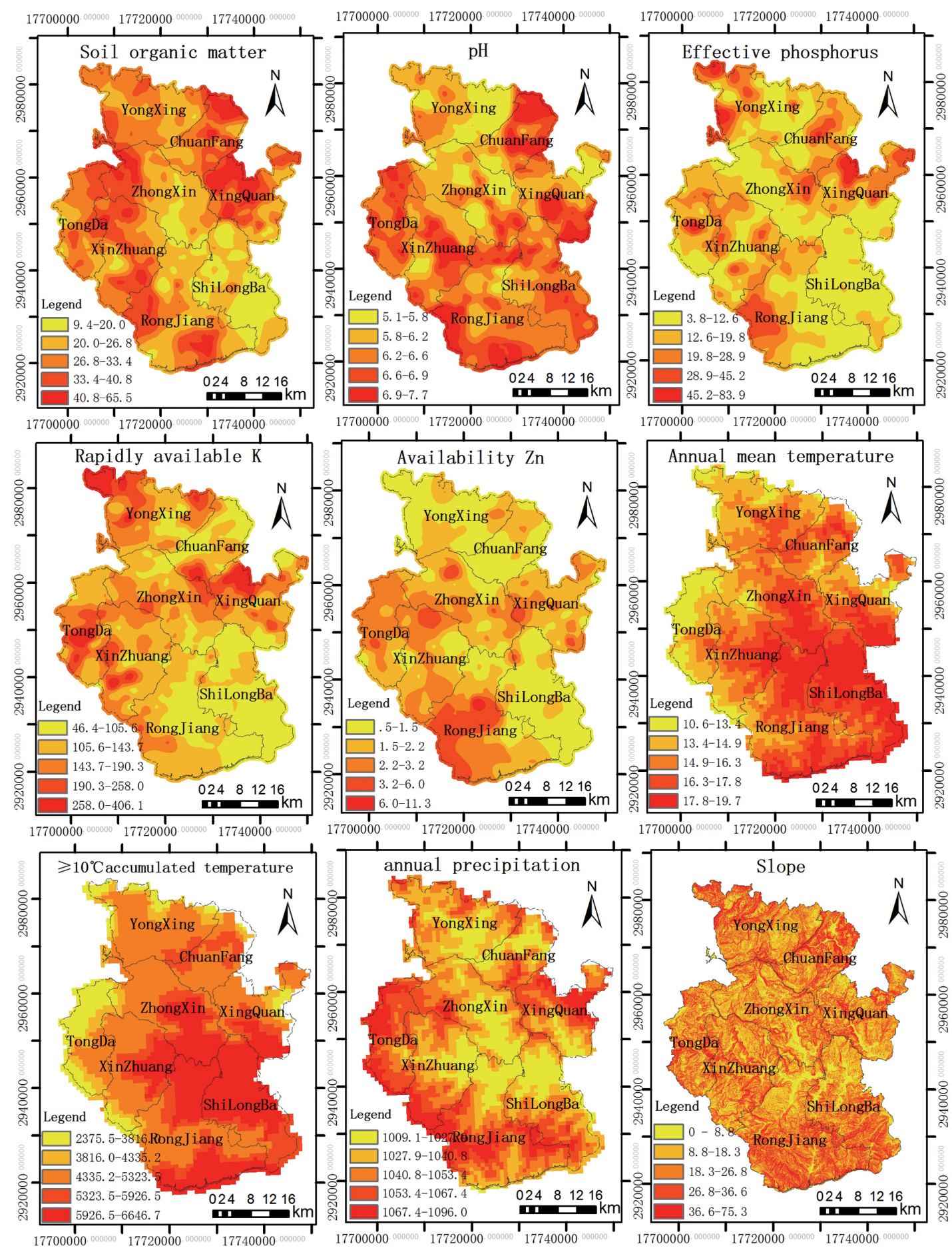

Fig. 4. Interpolation layers for part of the evaluation indices. 
Table 1. Evaluation index system and their weights of CLF.

\begin{tabular}{|c|c|c|c|c|c|c|}
\hline \multicolumn{7}{|c|}{ Level A (CLF) } \\
\hline \multirow{3}{*}{ Level C (indices) } & \multicolumn{6}{|c|}{ Level B (5 aspects of factors) } \\
\hline & SM & $\mathrm{SC}$ & PCOS & SN & Weather & $\mathrm{CW}$ \\
\hline & 0.3279 & 0.2186 & 0.1726 & 0.1639 & 0.1171 & $\sum \mathrm{CiAi}$ \\
\hline Irrigation guarantee rate & 0.6087 & & & & & 0.1996 \\
\hline Drainage level & 0.2174 & & & & & 0.0713 \\
\hline Planting system & 0.1739 & & & & & 0.0570 \\
\hline Slope & & 0.4478 & & & & 0.0979 \\
\hline Elevation & & 0.2239 & & & & 0.0489 \\
\hline Geomorphic type & & 0.1493 & & & & 0.0326 \\
\hline Soil parent material & & 0.1791 & & & & 0.0391 \\
\hline Tillage layer thickness & & & 0.4719 & & & 0.0814 \\
\hline Profile configuration & & & 0.1348 & & & 0.0233 \\
\hline Soil texture & & & 0.2360 & & & 0.0407 \\
\hline $\mathrm{pH}$ & & & 0.1573 & & & 0.0271 \\
\hline Soil organic matter & & & & 0.4800 & & 0.0787 \\
\hline Effective phosphorus & & & & 0.2400 & & 0.0393 \\
\hline Rapidly available $\mathrm{K}$ & & & & 0.1600 & & 0.0262 \\
\hline Availability Zn & & & & 0.1200 & & 0.0197 \\
\hline$\geq 10^{\circ} \mathrm{C}$ accumulated temperature & & & & & 0.5000 & 0.0585 \\
\hline Annual precipitation & & & & & 0.2500 & 0.0293 \\
\hline Annual mean temperature & & & & & 0.2500 & 0.0293 \\
\hline
\end{tabular}

${ }^{1} \mathrm{SM}$ means soil management; SC means site conditions; PCOS means physicochemical characteristics of soil; SN means soil nutrient; $\mathrm{CW}$ means combination weight

error in interpolation calculation. Moreover, it can also estimate the spatial correlation between points and points by interpolation of some known points. Therefore, its results have good intrinsic correlation properties and accuracy [31].

In this study the soil nutrient indices such as $\mathrm{pH}$, soil organic matter, effective phosphorus and availability $\mathrm{Zn}$ are first obtained by physical or chemical means. Then, based on these sampling point coordinates as spatial reference, the Kriging spatial interpolation method is used to create some spatial layers for every soil nutrient (Fig. 4). The optimal interpolation formula of this method is as follows:

$$
Z\left(x_{0}\right)=\sum_{i=1}^{n} w_{i} Z\left(x_{i}\right)
$$

...where $\mathrm{Z}(\mathrm{x} 0)$ is interpolated estimate value on the unexposed point $\mathrm{x} 0$, wi is the weight coefficient associated with the measured point and $\mathrm{Z}(\mathrm{xi})$ is the measured value obtained at several points near $\mathrm{x} 0$.

\section{Delphi and AHP}

In this study, Delphi and AHP are combined to filtrate the evaluation index of CLF and calculate their weight. The process is as follows: First we invited specialists in soil fertility, agriculture and agronomy according to the characteristics of cultivated land resources and actual agricultural production in the study area. Second, we analyzed the key factors that affect the CLF carefully. According to the actual conditions in the study area, we selected 18 evaluation indices from 5 aspects of soil management, site conditions, physicochemical characteristics of soil, soil nutrient and weather to constitute the evaluation index system of CLF in the study area.

In addition, we further used AHP to analyze correlativity of these indices, and divide the orderly hierarchy corresponding to each index. On this basis, experts are asked to compare and judge for every index at every hierarchy in accordance with a given criterion, and provide the quantitative expression of relative importance for each index. Finally, we established the judgment matrix and solved its eigenvector and 
Table 2. Membership function of quantitative evaluation index factors in the study area.

\begin{tabular}{|c|c|c|c|c|c|}
\hline Factors & Type of function & Membership function & $\mathrm{a}$ & $\mathrm{c}$ & $\mathrm{ut}$ \\
\hline Irrigation guarantee rate & Ring & $\mathrm{y}=1 /\left(1+\mathrm{a}^{*}(\mathrm{u}-\mathrm{c})^{\wedge} 2\right)$ & 0.000395 & 96.2171 & 96.2171 \\
\hline Slope & Ring down & $\mathrm{y}=1 /\left(1+\mathrm{a}^{*}(\mathrm{u}-\mathrm{c})^{\wedge} 2\right)$ & 0.006923 & 1.1803 & 121.3700 \\
\hline Elevation & Ring down & $\mathrm{y}=1 /\left(1+\mathrm{a}^{*}(\mathrm{u}-\mathrm{c})^{\wedge} 2\right)$ & 0.000001 & 1200.0000 & 11200.0000 \\
\hline Tillage layer thickness & Ring & $\mathrm{y}=1 /\left(1+\mathrm{a}^{*}(\mathrm{u}-\mathrm{c})^{\wedge} 2\right)$ & 0.007863 & 26.8841 & 26.8841 \\
\hline PH & Peak & $\mathrm{y}=1 /\left(1+\mathrm{a}^{*}(\mathrm{u}-\mathrm{c})^{\wedge} 2\right)$ & 0.319288 & 6.7957 & 24.5000 \\
\hline Soil organic matter & Ring & $\mathrm{y}=1 /\left(1+\mathrm{a}^{*}(\mathrm{u}-\mathrm{c})^{\wedge} 2\right)$ & 0.001227 & 44.1565 & 44.1565 \\
\hline Effective phosphorus & Ring & $\mathrm{y}=1 /\left(1+\mathrm{a}^{*}(\mathrm{u}-\mathrm{c})^{\wedge} 2\right)$ & 0.001227 & 44.1565 & 44.1565 \\
\hline Rapidly available K & Ring & $\mathrm{y}=1 /\left(1+\mathrm{a}^{*}(\mathrm{u}-\mathrm{c})^{\wedge} 2\right)$ & 0.000082 & 204.9261 & 204.9261 \\
\hline Availability Zn & Ring & $\mathrm{y}=1 /\left(1+\mathrm{a}^{*}(\mathrm{u}-\mathrm{c})^{\wedge} 2\right)$ & 0.695504 & 2.1790 & 2.1790 \\
\hline$\geq 10^{\circ} \mathrm{C}$ accumulated temperature & Ring & $\mathrm{y}=1 /\left(1+\mathrm{a}^{*}(\mathrm{u}-\mathrm{c})^{\wedge} 2\right)$ & 0.000001 & 5500.0000 & 5500.0000 \\
\hline Annual precipitation & Ring & $\mathrm{y}=1 /\left(1+\mathrm{a}^{*}(\mathrm{u}-\mathrm{c})^{\wedge} 2\right)$ & 0.000003 & 1100.0000 & 1100.0000 \\
\hline Annual mean temperature & Ring & $\mathrm{y}=1 /\left(1+\mathrm{a}^{*}(\mathrm{u}-\mathrm{c})^{\wedge} 2\right)$ & 0.016961 & 18.6552 & 18.6552 \\
\hline
\end{tabular}

maximum eigenvalue to calculate the weight of importance for each index in every hierarchy.

In this process, the consistency check is especially important. Because of the complexity of the index itself and the idealization of the calculation process, it will lead to the error when we use AHP to calculate the weight. If we do not do a consistency test, then the weight of the index may be beyond the reasonable range or even wrong. Therefore, it is necessary to check the consistency and randomness for the judgment matrix. The test formula used is as follows:

$$
Q=(U \max -N) /(D \times(N-1))
$$

...where $\mathrm{Q}$ is the random consistency ratio of the judgment matrix, Umax is the largest eigenvalue of the judgment matrix, $\mathrm{N}$ is the order of the judgment matrix, Umax-N is called the consistency index of the judgment matrix and $\mathrm{D}$ is the average random consistency index. It is considered that the judgment matrix has satisfactory consistency and also indicates that the weight allocation is equitable when $\mathrm{Q}<0.1$ [32]. After the above treatment, we can get the following results of evaluation indices and their weights.

\section{Fuzzy Mathematics}

The membership degree theory of fuzzy mathematics can solve the problem of fuzziness and unquantifiability [33-35]. For this reason, in this paper we applied fuzzy mathematics to judge the function relationship between the indices and the CLF by the fuzzy subset and the membership function. Moreover, it can also identify the type of function it belongs to: ring function, ring down function, linear function, peak type function and conceptual function [36].
In this study, the membership degree refers to the degree of influence of a certain evaluation index on CLF at a certain value. When the degree of influence is fully matched, the membership degree is 1 . If the degree of influence is not matched completely, then the membership degree is 0 . When the degree of influence is partially matching, the membership degree is between 0 and 1 . Besides, the membership function represents an analytical function between the measured value of every evaluation index and the membership degree. Therefore, according to the membership function of each evaluation index, the corresponding membership degree can be calculated.

In this evaluation, the relationship between evaluation index and the CLF is divided into four types: ring function, ring down function, peak type function and conceptual function. Among them, for the irrigation guarantee rate, slope, elevation and other quantitative indices, we calculate their membership degree by constructing the membership function (Table 2), but for those unquantifiable indices, such as drainage level, soil parent material, aspect, etc. Delphi is used to give their membership degree (Table 3).

\section{Comprehensive Index Model of CLF (CIMCLF)}

Based on the weight calculated by Delphi and AHP, the membership degree is determined by fuzzy mathematics. Corresponding to each evaluation unit of CLF, we use the CIMCLF to calculate the comprehensive index of CLF for each evaluation unit. The formula is as follows:

$$
I F I=\sum_{i=1}^{n}(F i \times C i)
$$


Table 3. Membership degree of conceptual evaluation index factors in the study area.

\begin{tabular}{|c|c|c|}
\hline Factors & Type & Membership degree \\
\hline \multirow{5}{*}{ Drainage level } & Excellent & 1 \\
\hline & Good & 0.87 \\
\hline & Medium & 0.73 \\
\hline & Poor & 0.56 \\
\hline & Poorer & 0.3 \\
\hline \multirow{7}{*}{ Planting system } & Beans - Tobacco, Beans, Tobacco & 1 \\
\hline & Rape - beans, beans - vegetables, tobacco - rape & 0.95 \\
\hline & Tea, beans, rice - beans & 0.9 \\
\hline & Rape - corn, rice, tobacco - wheat & 0.85 \\
\hline & Fruit, potato & 0.8 \\
\hline & Corn, wheat, sugarcane & 0.75 \\
\hline & Wheat - corn & 0.7 \\
\hline \multirow{5}{*}{ Soil parent material } & Purple sand shale weathering & 1 \\
\hline & Alluvial, purple sand shale residue weathering & 0.95 \\
\hline & Muddy rock weathering matter, quartzite deposits, slope deposits & 0.85 \\
\hline & Red soil parent material, acid mother rock weathering, carbonate rock alluvial & 0.80 \\
\hline & Carbonate slope and residue & 0.75 \\
\hline \multirow{10}{*}{ Geomorphic type } & Lower terraces of rivers & 1 \\
\hline & High terraces of flat river & 0.92 \\
\hline & High terraces of ups and downs & 0.85 \\
\hline & Low platform of flat floodplain & 0.82 \\
\hline & Low platform of ups and downs & 0.80 \\
\hline & Table-land of ups and downs pluvial & 0.76 \\
\hline & Low platform of rolling erosion & 0.65 \\
\hline & Low mountains & 0.45 \\
\hline & Medium mountains & 0.35 \\
\hline & High mountains & 0.25 \\
\hline \multirow{4}{*}{ Profile configuration } & 'A-P-W', 'A-P-W-C' & 1 \\
\hline & 'A-P-C', 'A-P-B-C', 'A-P-B' & 0.9 \\
\hline & 'A-AB-B', 'A-B-C' & 0.8 \\
\hline & 'A-P-G' & 0.7 \\
\hline \multirow{6}{*}{ Soil texture } & Heavy loam & 1 \\
\hline & Middle loam & 0.95 \\
\hline & Sandy loam, light loam & 0.85 \\
\hline & Light clay & 0.80 \\
\hline & Medium clay & 0.75 \\
\hline & Sand & 0.7 \\
\hline
\end{tabular}

In this formula, IFI is the value of the comprehensive index of CLF. Fi is the membership degree of the i-th index, and $\mathrm{Ci}$ is the combination weight of the $\mathrm{i}$-th index.

According to the CIMCLF, to calculate IFI of CLF, then using the cumulative curve method to divide IFI into six classes as the grading standard of CLF in the study area. The results are shown in Table 4.

\section{Results and Discussion}

\section{Quantity of Cultivated Land in Every Class}

In this evaluation, the average value of IFI is 0.75 . The maximum value of IFI is 0.90 . The minimum value of IFI is 0.55 . According to values of the IFI, the level of CLF of $23830.63 \mathrm{hm}^{2}$ divide into 6 classes in the study area. Among them, class 1 cultivated land occupies 
Table 4. Grading standard of CLF in the study area.

\begin{tabular}{|c|c|}
\hline Classes & IFI \\
\hline Class 1 & $\geq 0.830$ \\
\hline Class 2 & $\geq 0.795$ AND $<0.830$ \\
\hline Class 3 & $\geq 0.755$ AND $<0.795$ \\
\hline Class 4 & $\geq 0.710$ AND $<0.755$ \\
\hline Class 5 & $\geq 0.665$ AND $<0.710$ \\
\hline Class 6 & $<0.665$ \\
\hline
\end{tabular}

558 evaluation units with an area of $2676.39 \mathrm{hm}^{2}$. Class 2 cultivated land occupies 1216 evaluation units with an area of $4283.23 \mathrm{hm}^{2}$. Class 3 cultivated land occupies 2445 evaluation units with an area of $6907.39 \mathrm{hm}^{2}$. Class 4 cultivated land occupies 2063 evaluation units with an area of $4874.37 \mathrm{hm}^{2}$. Class 5 cultivated land occupies 1259 evaluation units with an area of $2782.41 \mathrm{hm}^{2}$. Class 6 cultivated land occupies 859 evaluation units with an area of $2306.84 \mathrm{hm}^{2}$. The classification results are shown in Table 5 .

From Table 5 we can see that the area of the Class 3 cultivated land is the largest, which is $6907.39 \mathrm{hm}^{2}$, accounting for $28.99 \%$ of the total cultivated land area. Following are Classes 4 and 2, for which the areas are $4874.37 \mathrm{hm}^{2}$ and $4283.23 \mathrm{hm}^{2}$, accounting for $20.45 \%$ and $17.97 \%$ of the total cultivated land area respectively. The area of the Class 6 cultivated land is the smallest, which is $2306.84 \mathrm{hm}^{2}$, accounting for $9.68 \%$ of the total cultivated land area.
From the perspective of land use types, there are only paddy fields and dry lands in all cultivated land. Among them, firstly the drylands area in Class 3 is the largest, which is $5842.32 \mathrm{hm}^{2}$, accounting for $32.22 \%$ of the total drylands area. Secondly are Classes 4 and 5 , of which the drylands areas are $4280.53 \mathrm{hm}^{2}$ and $2724.15 \mathrm{hm}^{2}$, respectively, and the proportion of the total area of drylands is $23.61 \%$ and $15.02 \%$. Finally, the least drylands area is Class 1 cultivated land, at only $548.03 \mathrm{hm}^{2}$, accounting for $3.03 \%$ of the total drylands area. Obviously, the site conditions and nutrient status of paddy fields are better than drylands. Therefore, with increases of these classes, the area of paddy fields decreased gradually in the study area. This is reflected in that the area of paddy fields is the largest in the Class 1 cultivated land, with $2128.36 \mathrm{hm}^{2}$, accounting for $37.35 \%$ of the total area of paddy fields in the study area, but there have been no paddy fields in the Class 6 cultivated land.

\section{Spatial Distribution of Cultivated Land in Every Class}

From the view of spatial distribution of cultivated land in every class, we can see that the class 1 cultivated land is mainly distributed in the region of Rong Jiang, with an area of $806.95 \mathrm{hm}^{2}$, accounting for $30.15 \%$ of the total area of cultivated land in Class 1 . The second region of Class 1 cultivated land is distributed in ShiLongBa, whose area is $504.39 \mathrm{hm}^{2}$, accounting for $18.85 \%$ of the total area of cultivated land in Class 1.

Table 5. Classification result of CLF for every class in the study area.

\begin{tabular}{|c|c|c|c|c|c|c|c|}
\hline Classes & $\begin{array}{c}\text { Name of land } \\
\text { type }\end{array}$ & $\begin{array}{c}\text { Number of } \\
\text { evaluation units }\end{array}$ & $\begin{array}{l}\text { Area } \\
\left(\mathrm{hm}^{2}\right)\end{array}$ & $\begin{array}{l}\text { Proportion for } \\
\text { paddy fields }\end{array}$ & $\begin{array}{l}\text { Proportion for } \\
\text { drylands }\end{array}$ & $\begin{array}{l}\text { Proportion for the } \\
\text { class of itself }\end{array}$ & $\begin{array}{l}\text { Proportion for } \\
\text { cultivated land }\end{array}$ \\
\hline \multirow{3}{*}{ Class 1} & Paddy fields & 320 & 2128.36 & 37.35 & -- & 79.52 & 8.93 \\
\hline & Drylands & 238 & 548.03 & -- & 3.03 & 20.48 & 2.30 \\
\hline & Subtotal & 558 & 2676.39 & 37.35 & 3.03 & 100.00 & 11.23 \\
\hline \multirow{3}{*}{ Class 2} & Paddy fields & 436 & 1852.91 & 32.52 & -- & 43.26 & 7.78 \\
\hline & Drylands & 780 & 2430.32 & -- & 13.40 & 56.74 & 10.20 \\
\hline & Subtotal & 1216 & 4283.23 & 32.52 & 13.40 & 100.00 & 17.97 \\
\hline \multirow{3}{*}{ Class 3} & Paddy fields & 407 & 1065.07 & 18.69 & -- & 15.42 & 4.47 \\
\hline & Drylands & 2038 & 5842.32 & -- & 32.22 & 84.58 & 24.52 \\
\hline & Subtotal & 2445 & 6907.39 & 18.69 & 32.22 & 100.00 & 28.99 \\
\hline \multirow{3}{*}{ Class 4} & Paddy fields & 222 & 593.84 & 10.42 & -- & 12.18 & 2.49 \\
\hline & Drylands & 1841 & 4280.53 & -- & 23.61 & 87.82 & 17.96 \\
\hline & Subtotal & 2063 & 4874.37 & 10.42 & 23.61 & 100.00 & 20.45 \\
\hline \multirow{3}{*}{ Class 5} & Paddy fields & 20 & 58.26 & 1.02 & -- & 2.09 & 0.24 \\
\hline & Drylands & 1239 & 2724.15 & -- & 15.02 & 97.91 & 11.43 \\
\hline & Subtotal & 1259 & 2782.41 & 1.02 & 15.02 & 100.00 & 11.68 \\
\hline \multirow{2}{*}{ Class 6} & Drylands & 859 & 2306.84 & -- & 12.72 & 100.00 & 9.68 \\
\hline & Subtotal & 859 & 2306.84 & -- & 12.72 & 100.00 & 9.68 \\
\hline \multicolumn{2}{|r|}{ Total } & 8400 & 23830.63 & -- & -- & -- & -- \\
\hline
\end{tabular}




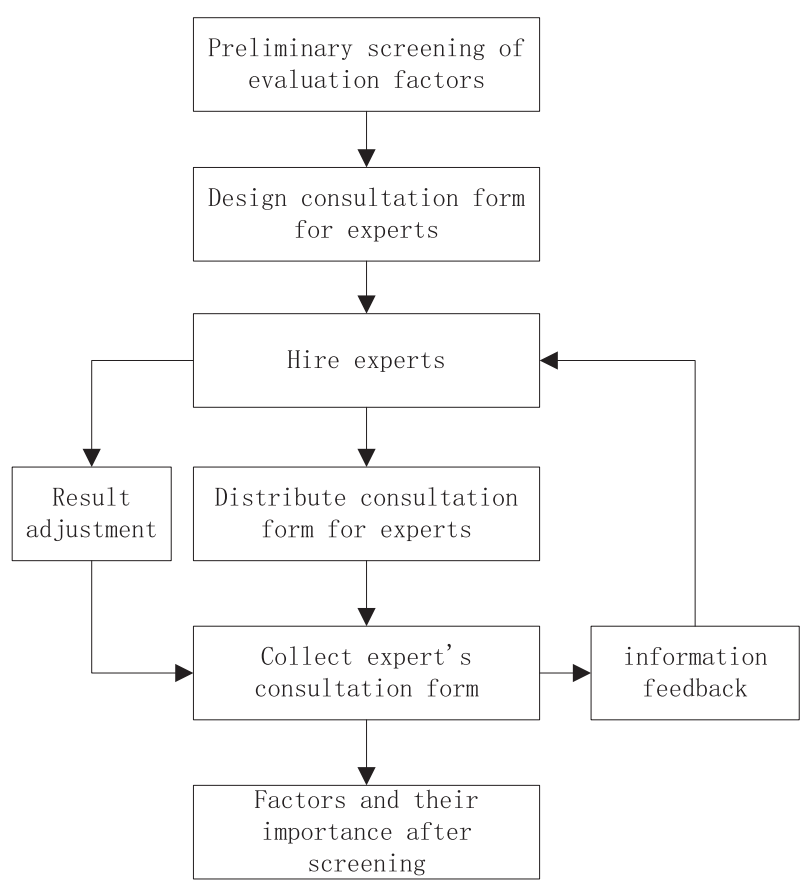

Fig. 5. Process for selecting evaluation indices.

Class 2 cultivated land also mainly is distributed in RongJiang. Its area is largest, at $901.55 \mathrm{hm}^{2}$, accounting for $21.05 \%$ of the total area of cultivated land in Class 2. The second region of the Class 2 cultivated land is distributed in ZhongXin, whose area is $826.08 \mathrm{hm}^{2}$, accounting for $19.29 \%$ of the total area of cultivated land in Class 2.

Class 3 cultivated land is mainly distributed in the region of ZhongXin, with an area of $1391.98 \mathrm{hm}^{2}$, accounting for $20.15 \%$ of the total area of cultivated land in Class 3. The next region of Class 3 cultivated land is also distributed in RongJiang, whose area is $1090.80 \mathrm{hm}^{2}$, accounting for $15.79 \%$ of the total area of cultivated land in Class 3 .

Class 4 cultivated land is mostly distributed in the region of YongXing, with an area of $1069.81 \mathrm{hm}^{2}$, accounting for $21.95 \%$ of the total area of cultivated land in Class 4. Secondly, the area of the Class 4 cultivated land in XinZhuang and ZhongXin is $731.93 \mathrm{hm}^{2}$ and $639.81 \mathrm{hm}^{2}$ with proportions of $15.02 \%$ and $13.13 \%$, respectively.

Class 5 cultivated land is mainly distributed in YongXing, ZhongXin and XinZhuang. The areas are $526.84 \mathrm{hm}^{2}, 737.01 \mathrm{hm}^{2}$ and $438.22 \mathrm{hm}^{2}$, and the proportions are $18.93 \%, 18.27 \%$ and $15.75 \%$, respectively.

Class 6 cultivated land is mostly distributed in YongXing, TongDa and ZhongXin. The areas are $620.47 \mathrm{hm}^{2}, 469.84 \mathrm{hm}^{2}$ and $324.23 \mathrm{hm}^{2}$, accounting for the proportion of the total area of the Class 6 cultivated land, which is $26.90 \%, 20.37 \%$ and $14.06 \%$, respectively.

In general, the spatial distribution of CLF shows an attenuation trend that comes from the center of the river valley to its surroundings. Class 1 cultivated land is mainly distributed on both sides of the river valley and nearby village, and this part of the cultivated land belongs to the field of high and stable yield. The class 2 cultivated land is mostly distributed in the semimountainous region whose elevation is below $1700 \mathrm{~m}$, or slightly far from the valley, and in this part of the cultivated land irrigation and drainage conditions is better too. Class 3 cultivated land is generally distributed in the riverside mountainous areas of valleys or the mountainous areas where elevation is between 1700 and $2300 \mathrm{~m}$. Class 4 cultivated land is mainly distributed in the river terrace or gentle slope areas whose elevation is between 2300 and $2500 \mathrm{~m}$. In general, the irrigation conditions in these regions are ordinary. Its irrigation guarantee rate is below $60 \%$. Class 5 cultivated land is mainly distributed in the hilly region on both sides of the Jinsha River, whose elevation in $1500 \mathrm{~m}$ above. Class 6 cultivated land distribution is scattered relatively. They are mainly located in the valley area, the region of mountains or semi-mountainous with elevation $1800 \mathrm{~m}$ above. The irrigation conditions of this part of the cultivated land are poor. Therefore food production in these regions is relatively low and unstable.
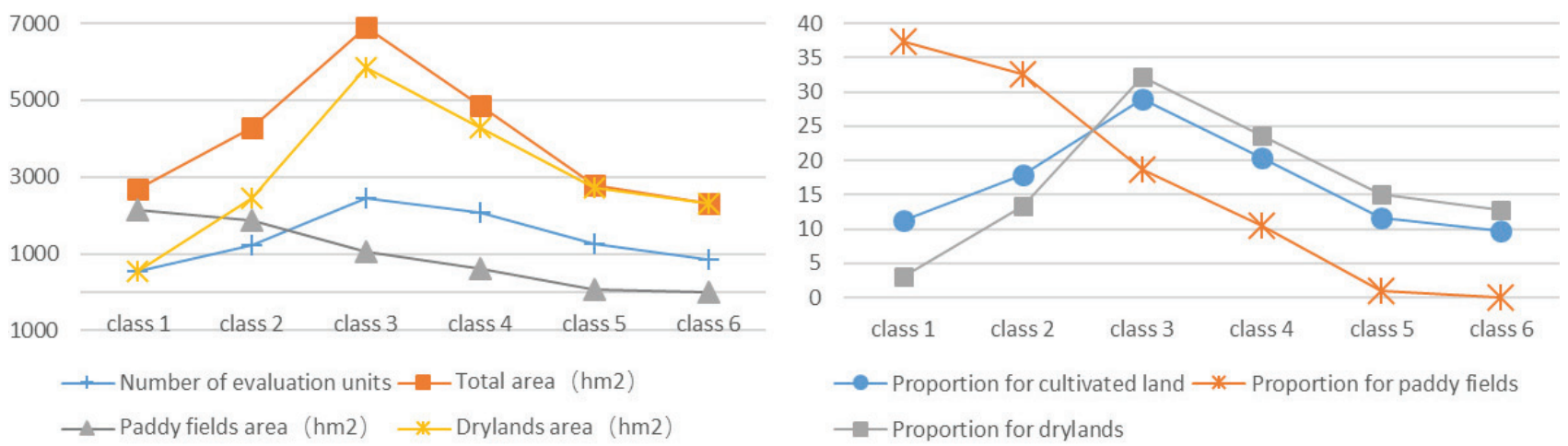

Fig. 6. Broken line diagram for the classification result. 


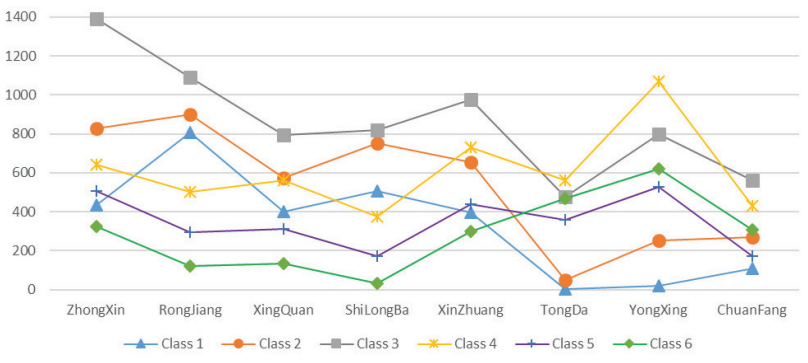

Fig. 7. Areas of cultivated land in every class in spatial distribution.

\section{Soil Fertility Characteristics of Cultivated Land in Every Class}

The results of overlay analysis based on the soil type data and the spatial interpolation data of soil nutrients show that the soil species of Class 1 cultivated land belongs mainly to the tidal sand mud and yellow sand mud of paddy soil. The soil layer is thick and fertile. Its utilization condition is unlimited. Therefore, it is suitable for planting most crops. The soil species of Class 2 cultivated land mainly also is involved in paddy soil, such as the clay gouge, purple soil, red mud and yellow clay soil. Soil fertility is medium, but the supply capacity of fertilizer is not coordinated. Therefore, its utilization condition has some restrictions. The soil species of Class 3 cultivated land mainly involves duck excrement mud, cold sand mud, yellow clay and little red mud in the paddy soil. Because the fertility of this kind of soil is insufficient, the retention performance for water and fertilizer is poor. Therefore, this kind of soil is highly selective for crops. The main soil species of the class 4 cultivated land are yellow soil, brown soil, clay soil and sandy soil. Their soil fertility is obviously insufficient due to obvious soil erosion. The soil species of the class 5 cultivated land are mainly brown red soil, red soil and yellow red soil. The soil fertility is low, and the cultivated land is usually slope cropland. The soil of the Class 6 cultivated land is mainly yellow red

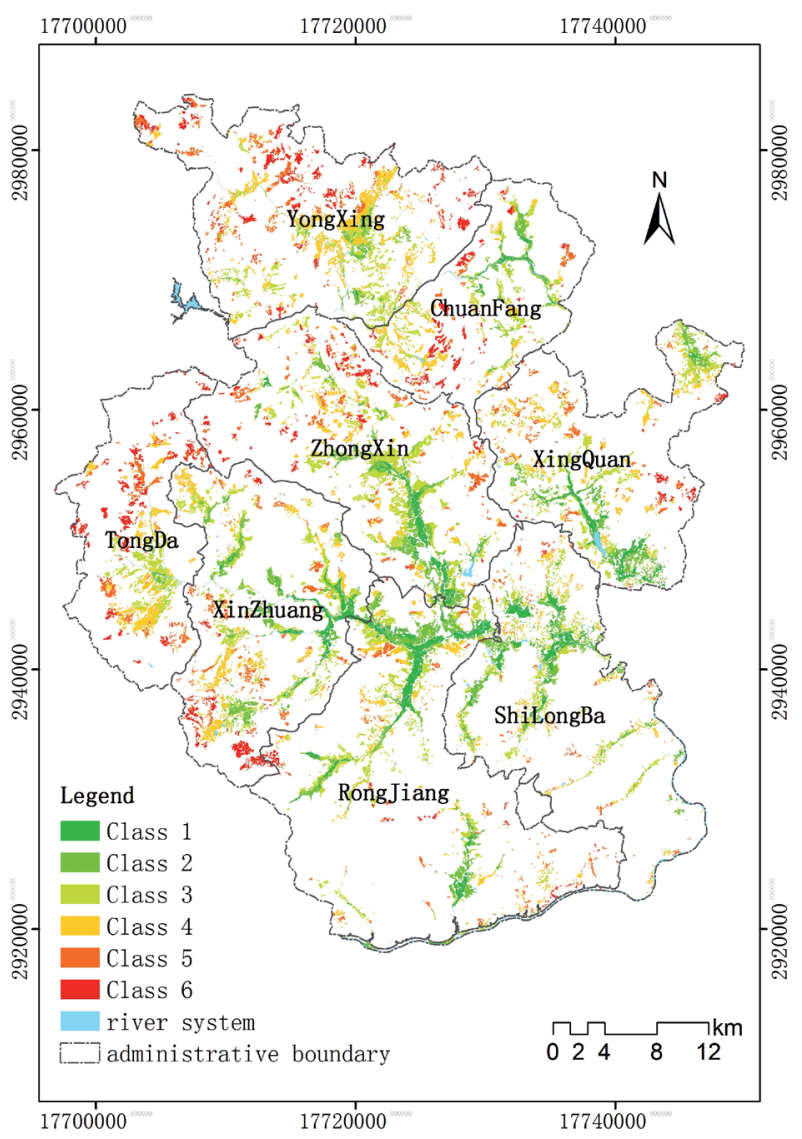

Fig. 8. Spatial distribution of CLF in the study area.

soil, yellow brown soil and black lime soil. Because most slopes of cultivated land are large, soil erosion is serious, the soil layer is also shallow and soil fertility is relatively poor in Class 6 cultivated land.

\section{Conclusions}

This paper explores a set of technical methods and working ideas of the evaluation and grading of CLF

Table 6. Spatial distribution of cultivated land in every class in the study area.

\begin{tabular}{|c|c|c|c|c|c|c|c|}
\hline Administrative region & Class 1 & Class 2 & Class 3 & Class 4 & Class 5 & Class 6 & Total \\
\hline ZhongXin & 436.63 & 826.08 & 1391.98 & 639.81 & 508.3 & 324.23 & 4127.03 \\
\hline RongJiang & 806.95 & 901.55 & 1090.8 & 503.4 & 293.41 & 121.11 & 3717.22 \\
\hline XingQuan & 402.58 & 575.09 & 792.29 & 562.78 & 310.76 & 132.83 & 2776.33 \\
\hline ShiLongBa & 504.39 & 752.1 & 819.81 & 376.68 & 174.08 & 31.26 & 2658.32 \\
\hline XinZhuang & 397.38 & 656.13 & 976.1 & 731.93 & 438.22 & 299.96 & 3499.72 \\
\hline TongDa & 2.14 & 48.68 & 474.82 & 560.06 & 357.46 & 469.84 & 1913 \\
\hline YongXing & 18.77 & 253.15 & 798.94 & 1069.81 & 526.84 & 620.47 & 3287.98 \\
\hline ChuanFang & 107.55 & 270.45 & 562.65 & 429.90 & 173.34 & 307.14 & 1851.03 \\
\hline Total & 2676.39 & 4283.23 & 6907.39 & 4874.37 & 2782.41 & 2306.84 & 23830.63 \\
\hline
\end{tabular}


using GIS spatial analysis technologies, Delphi, AHP, fuzzy mathematics and the comprehensive index model. On this basis, we take the survey project of CLF of Huaping, a county in the middle reaches of the Jinsha River in China to carry out an empirical study. Through the above research, we draw the following main conclusions:

1) In the division of the evaluation units, GIS spatial overlay technology is used to superimpose the administrative division layer, the land use layer, the soil nutrient layer and the soil type distribution layer, which can provide clear information about administrative affiliation and soil properties for each evaluation unit. This approach allows for both the comparability and the differentiation of each evaluation unit.

2) The kriging spatial interpolation method is used for spatial interpolation processing for the soil nutrient sampling points in the study area. The method can ensure that the spatial correlation of these sampling points is fully considered. As a result, the soil nutrient spatial data will have a good intrinsic correlation and accuracy in this processing. In addition, through the spatial distribution layers of soil nutrients we can intuitively grasp the spatial distribution characteristic of soil nutrients in the study area.

3) The Delphi and the AHP are used in the selection of evaluation index and the calculation for their weights. Furthermore, fuzzy mathematics is also used to construct the membership functions of evaluation indices. This method combines quantitative analysis with qualitative analysis to ensure that the results are more scientific and reliable.

4) CIMCLF based on GIS are constructed. The result shows that it can directly distribute the level of grading into the specific geographic space and ensure that the grading result has a good spatial visualization effect.

In conclusion, the organic integration method proposed in this paper makes the process of the evaluation and grading of the CLF achieve quantification, visualization and automation. The result of the evaluation and grading can also express the spatial differences of CLF, which is more consistent with the objective reality of the CLF in the study area.

\section{Acknowledgements}

The authors gratefully acknowledge financial support by the National Natural Science Foundation of China (No. 41161062) and the doctoral research project of Yunnan Normal University (No. 01000205020503063).

\section{Conflict of Interest}

Yuan Lei and Yang Kun designed the paper. Chen Guoping collected and analyzed the data. Yuan Lei revised the paper. All authors contributed to the modification. All authors have read and approved the final manuscript. The authors declare no conflict of interest.

\section{References}

1. WANG L., LV X., LIU H. Research of Evaluation on Cultivated Land Fertility in Xinjiang Desert Oasis Based on GIS Technology - Taking No. 22 State Farm as the Example, the 4th ifip international on computer and computing technologies in agriculture and the $4^{\text {th }}$ symposium on development of rural information. 290, 2017.

2. HUDDLESTON J.H. Development and use of soil fertility ratings in the United States. Geoderma, 32 (4), 297, 1984.

3. YAN YIFAN, LIU JIANLI, ZHANG JIABAO Evaluation method and model analysis for fertility of cultivated land. Transactions of the Chinese Society of Agricultural Engineering, 30 (5), 204, 2014.

4. LUO R., HE T. Application Comparison of Two Methods in Fertility Evaluation of Cultivated Land in Mountainous Area. Shandong Agricultural Sciences, 45 (11), 91, 2013.

5. ZHANG Q.C., YOU-HUA M.A., YANG S.H.,XIAOGANG L.I., WANG J. Evaluation of Cultivated Land Fertility in Wuhu City based on GIS. Resources \& Environment in the Yangtze Basin, 25 (2), 226, 2016.

6. LIU Z.W. Research on Investigation and Evaluation of Cultivated Land Fertility in Mouding County. Journal of Anhui Agricultural Sciences, 45 (31), 128, 136, 2017.

7. ZHANG Z.H., REN J. Evaluation of Cultivated Land Fertility Based on GIS. Journal of Anhui Agricultural Sciences, 42 (15), 4813, 2014.

8. OTGONBAYAR M., ATZBERGER C., CHAMBERS J., AMARSAIKHAN D., BOCK S., TSOGTBAYAR J. Land Suitability Evaluation for Agricultural Cropland in Mongolia Using the Spatial MCDM Method and AHP Based GIS. Journal of Environmental Protection, 05 (9), 238, 2017.

9. CHEN Z. Application of Fuzzy Matter Element Analysis to Cultivated Land Evaluation. Anhui Agricultural Science Bulletin, 14 (11), 55, 233, 2008.

10. ZHOU X., AN Y.L., XU W.C., D MAO LIN Fuzzy evaluation on soil fertility of cultivated land based on GIS and improved AHP-a Case of Puan County in Guizhou Province. Chinese Journal of Soil Science, 40 (1), 51, 2009.

11. LIU C., SONG Z., SONG L., XU J. GIS-based Cultivated Land Fertility with Fuzzy Variable Weight. Chinese Agricultural Science Bulletin, 28 (14), 223, 2012.

12. ZHI W., ZHANG X.J. Evaluation of Cultivated Land Fertility Based on GIS at County Level. Asian Agricultural Research, 04 (7), 41, 2012.

13. XIE W., ZHAO X.M., GUO X., ZHANG J.J., LI T., XIA K. Evaluation on Cultivated Land Fertility at City Level by Using GIS. Chinese Journal of Soil Science, 46 (4), 810, 2015.

14. NIE Y., YU J., PENG Y., et al. A Comprehensive Evaluation of Soil Fertility of Cultivated Land: A GISBased Soil Basic Niche-Fitness Model. Communications in Soil Science \& Plant Analysis, 47 (5), 670, 2016.

15. CETIN M., ADIGUZEL F., KAYA O., SAHAP A. Mapping of bioclimatic comfort for potential planning using GIS in Aydin. Environment, Development and Sustainability, 20 (1), 361, 2018. 
16. KAYA E., AGCA M., ADIGUZEL F., CETIN M. (2018). Spatial data analysis with R programming for environment. Human and Ecological Risk Assessment: An International Journal. https://doi.org/10.1080/10807039.2018.1470896

17. WANG R., ZHAO G., CHEN L. Evaluation model of cultivated land fertility using artificial neural network and fertility and its application. Transactions of the Chinese Society of Agricultural Engineering, 24 (1), 113, 2008.

18. ROVLIAS A., KOTSOU S. Classification and regression tree for prediction of outcome after severe head injury using simple clinical and laboratory variables. Journal of Neurotrauma, 21 (7), 886, 2004.

19. CAO L.Y., SUN X., ZHAO Y., CHEN G. Evaluation on Soil Fertility Grade for Cultivated Land Based on Decision Trees. Journal of Northeast Forestry University, 39 (2), 93, 2011.

20. QIAO-MEI S.I., SONG L. Application of Decision Tree in Grade Evaluation of Arable Land Fertility. Journal of Anhui Agricultural Sciences, 39 (12), 7328, 7417, 2011.

21. LIU H., ZHANG X., CAO L., LI D. A study on evaluation of farmland fertility levels based on optimization of the decision tree algorithm, International Conference on Computer Science and Network Technology. IEEE, 158, 2013.

22. CETIN M., SEVIK H., CANTURK U., CAKIR C. Evaluation of the recreational potential of Kutahya Urban Forest. Fresenius Environmental Bulletin, 27 (5), 2629, 2018.

23. CETIN M., ZEREN I., SEVIK H., CAKIR C., AKPINAR H. A study on the determination of the natural park's sustainable tourism potential. Environmental Monitoring and Assessment, 190 (3), 167, 2018.

24. CETIN M., SEVIK H. (2016). Assessing Potential Areas of Ecotourism through a Case Study in Ilgaz Mountain National Park, InTech, Chapter 5, Eds:Leszek Butowski, 190, ISBN:978-953-51-2281-4, 81-110.

25. CETIN M. Determination of bioclimatic comfort areas in landscape planning: A case study of Cide Coastline, Turkish Journal of Agriculture-Food Science and Technology, 4 (9), 800, 2016.

26. CETIN M. Sustainability of urban coastal area management: a case study on Cide, Journal of Sustainable Forestry, 35 (7), 527, 2016.
27. CETIN M. Using GIS analysis to assess urban green space in terms of accessibility: case study in Kutahya. International Journal of Sustainable Development \& World Ecology, 22 (5), 420, 2015.

28. XIE Y.W., ZHAO J., YONG L.I., YAN F.X., ZHANG J.M. Assessment of cropland productivity based on GIS for typical black soil region at Hailun County. Arid Land Geography, 34 (2), 325, 2011.

29. ULAK M.B., OZGUVEN E.E., SPAINHOUR L., VANLI O.A. Spatial investigation of aging-involved crashes: A GIS-based case study in Northwest Florida. Journal of Transport Geography, 58, 71, 2017.

30. LI HAIQIANG, GUO CHENGJIU, LI YONG Variation characteristics of soil nutrients in sloping farmland with measures of soil and water conservation based on GIS. Research of Soil and Water Conservation, 24 (2), 43, 2017.

31. MURPHY R.R., CURRIERO F.C., BALL W.P. Comparison of spatial interpolation methods for water quality evaluation in the Chesapeake Bay. Journal of Environmental Engineering, 136 (2), 160, 2016.

32. YUAN L., ZHAO J., LI H., ZHANG M., CHEN G., ZHOU B. Exploitation suitability evaluation and potential area zoning for arable unused land in mountainous areas of Yunnan province. Transactions of the Chinese Society of Agricultural Engineering, 29 (16), 229, 2013.

33. WANG L.J., ZHAO Y.G., GUO M., ZHANG G.L. Evaluation of farmland fertility based on GIS and Fuzzy Mathematics Theory at county level. Soils, 42 (1), 131, 2010.

34. WANG Z., CHEN W., ZHANG G. Empirical study on land intensive use and influencing factors of resource-based cities. Areal Research and Development, 31 (6), 106, 2012.

35. SARKHEIL H., RAHBARI S. Development of case historical logical air quality indices via fuzzy mathematics (Mamdani and Takagi-Sugeno systems), a case study for Shahre Rey Town. Environmental Earth Sciences, 75 (19), 1319, 2016.

36. FENG X.J, LEI G.P., ZHANG H., ZHOU H. Evaluation of the farmland fertility of Qianshao farm based on GIS. Research of Soil and Water Conservation, 21 (1), 198, 2014. 